\title{
Epiploic appendagitis diagnosis linked to intestinal symptoms: Case reports
}

\author{
Ronny Ronny 1,2,*

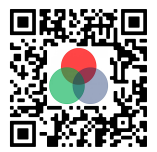 \\ Use your smartphone to scan this \\ QR code and download this article
}

${ }^{I}$ Department of Radiology, School of Medicine and Health Sciences, Atma Jaya Catholic University of Indonesia, Jakarta, Indonesia

${ }^{2}$ Department of Radiology, Atma Jaya Hospital, Jakarta, Indonesia

\section{Correspondence}

Ronny Ronny, Department of Radiology, School of Medicine and Health Sciences, Atma Jaya Catholic University of Indonesia, Jakarta, Indonesia

Department of Radiology, Atma Jaya Hospital, Jakarta, Indonesia

Email: ronny@atmajaya.ac.id

History

- Received: Aug 23, 2020

- Accepted: Oct 23, 2020

- Published: Oct 31, 2020

DOI : 10.15419/bmrat.v7i10.643

\section{Check for updates}

\section{Copyright}

(c) Biomedpress. This is an openaccess article distributed under the terms of the Creative Commons Attribution 4.0 International license.

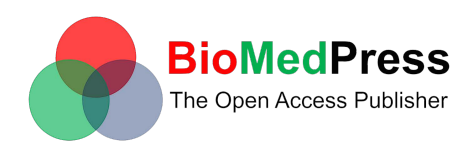

\begin{abstract}
Epiploic appendices are small pouches filled with projection-like fat structure adjacent to the antimesenteric side of the colon wall; they range in size from 0.5 to $5 \mathrm{~cm}$ and provide vascularization from small arterioles. Epiploic appendagitis is a benign condition of the epiploic appendices which leads to ischemia of the structure. Ischemia, therefore, causes localized sharp abdominal pain. Though uncommon, its symptoms can be diagnosed as acute lower abdominal pain since the symptoms could mimic diverticulitis and appendicitis. Thus, to diagnose epiploic appendagitis in this case, a CT scan was conducted to detect a fat-dense lesion of ovoid-like structure close to the colon. Given the good response to conservative management, establishing a correct diagnosis could help to minimize inappropriate invasive management.

Key words: Acute abdominal pain, inflammation, CT scan, epiploic appendagitis
\end{abstract}

\section{INTRODUCTION}

Epiploic appendices are small pouches filled with projection-like fat structures adjacent to the antimesenteric side of the colon wall. The appendices range from 0.5 to $5 \mathrm{~cm}$ and provide vascularization from small arterioles ${ }^{1}$. Epiploic appendagitis will be referred to hereafter as appendagitis. It is considered a self-limiting benign condition caused by torsion or thrombosis which leads to ischemia of the fat structures. Ischemia, in turn, causes localized sharp abdominal pain, especially on the lower left abdomen quadrant (in $76 \%$ of cases) ${ }^{2,3}$. Appendagitis mostly affects male patients in their $40 \mathrm{~s}$ to $50 \mathrm{~s}^{1,3}$. In the case of appendagitis, it is often overlooked or misdiagnosed since the acute lower abdominal pain symptoms associated with it can mimic diverticulitis and appendicitis.

Appendagitis shows clinical signs of localized peritoneal inflammation with specific imaging findings of localized fat density with ovoid-like structures close to the colon when imaged by computed tomography (CT) ${ }^{4}$. Herein, we report three men with abdominal pain who were diagnosed with appendagitis. Given the rarity of cases of appendagitis and that its symptoms often mimic symptoms of diverticulitis and appendicitis $^{5}$, it is important to consider appendagitis as one of the possible diagnoses for abdominal pain to minimize unnecessary invasive management.

\section{CASE PRESENTATION}

\section{Patient 1}

A 48-year-old male complaining of pain in the right lower quadrant abdomen which started 24 hours prior was admitted to the Emergency department. On the admission day, he had a sharp pain which arose suddenly and was localized. He was hemodynamically stable and had a body mass index (BMI) of $31 \mathrm{~kg} / \mathrm{m}^{2}$. However, this patient had no fever. On examination, his cardiorespiratory test was normal, but he had tenderness in his right lower quadrant abdomen. Blood tests showed mild leukocytosis $\left(10.3 \times 10^{3} / \mathrm{mm}^{3}\right)$. He had no history of surgery nor intake of medications. The patient was suspected as having appendicitis and was then referred to the Radiology department for CT scan. The scan revealed pericaecal lesion with fat attenuation and hyperattenuating rim, measuring $1.11 \times 0.81 \times 3 \mathrm{~cm}$. There was also fat stranding observed adjacent to the lesion and multiple lymphadenopathies mesenterial to the right lower quadrant (RLQ). However, the appendix was normal, and the rest of the evaluation was unremarkable (Figure 1). Therefore, the patient was diagnosed as having epiploic appendagitis.

The patient was given conservative treatment with bed rest and non-steroid anti-inflammatory drugs (NSAIDs). His symptoms were relieved, and he was discharged 2 days later with good condition.

\section{Patient 2}

A healthy 35-year-old male came to the internal medicine practice with a 72-hour history of left iliac

\author{
reports. Biomed. Res. Ther.; $/(10): 4066-40 / 0$.
}




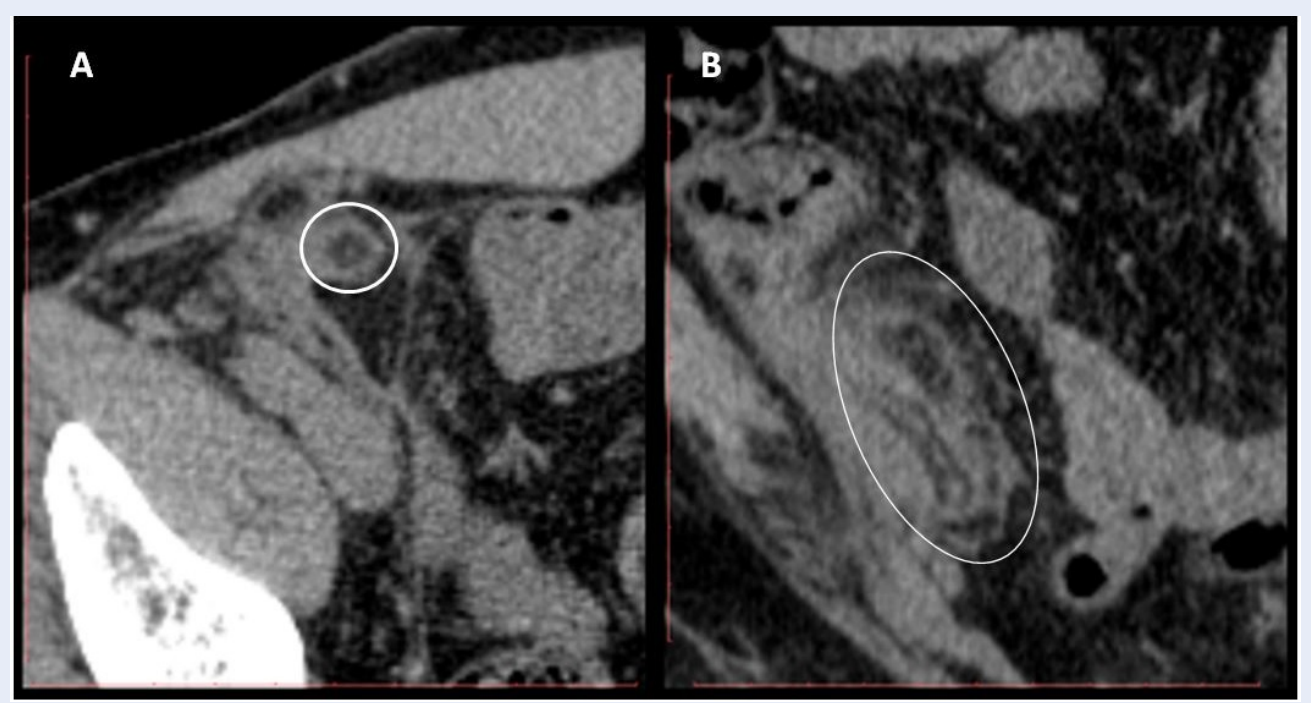

Figure 1: Non-enhanced abdominal CT scan of (a) axial and (b) coronal pericaecal lesions with fat attenuation and hyperattenuating rim, measuring $1.11 \times 0.81 \times 3 \mathrm{~cm}$. There was also fat stranding adjacent to the lesion and multiple lymphadenopathies mesenteric of the right lower quadrant (RLQ).

fossa pain. The sharp pain occurred suddenly. Prior to it, the patient had never experienced radiating pain, nor experienced symptoms or pain in the bowel or genitourinary areas. He had no history of fever or abdominal trauma. He felt uncomfortable during the examination. His condition was apyrexial, was hemodynamically stable, and with a body mass index of $23.87 \mathrm{~kg} / \mathrm{m}^{2}$.

The examination of cardiorespiratory functions showed normal sign. However, his abdomen showed signs of local tenderness in the left iliac fossa. Blood tests showed no sign of elevated inflammatory markers. The symptoms were not adequate enough to establish a diagnosis so a CT scan of the patient's abdomen was conducted.

The result showed that there was an ovoid-like structure of fat attenuation. The high-attenuation of fat showed in the rim, which appeared from the anterior wall of the descending colon, was encircled by mesenteric fat stranding that was inflamed, but had no bowel wall thickening (Figure 2). The patient was admitted to the surgical ward and treated with symptomatic medication, NSAIDs and antibiotics. The patient was in good condition and his symptoms were completely resolved after the $3 \mathrm{rd}$ day of hospital admission.

\section{Patient 3}

A 40-year-old male exhibited pain for 3 days in the left lower quadrant abdomen. No nausea, vomiting or change in bowel habits were indicated. The vital signs of the patient were in the normal range; his body mass index was $20.5 \mathrm{~kg} / \mathrm{m}^{2}$. However, physical examination showed tenderness and guarding in the left lower quadrant abdomen. Complete blood count showed a mild leukocytosis $\left(10.5 \times 10^{3} / \mathrm{mm}^{3}\right)$.

The patient was referred to the Radiology department with a concern for diverticulitis. Non-enhanced abdominal CT scan showed a fat density lesion with ovoid-like structure (with surrounding inflammation), measuring about $1.7 \times 3 \times 3.16 \mathrm{~cm}$ which abutted the sigmoid colon (Figure 3 ). This feature was suggestive of epiploic appendagitis. The appendix was normal and the rest of the study was unremarkable. The patient received some symptomatic medication and antibiotics for home care.

\section{DISCUSSION}

Epiploic appendices are subserous lobulated fat structures adjacent to the external surface of taenia coli, approximately 50 - 100 in number, found predominantly on the anterior and posterolateral surfaces ${ }^{6}$. They vary in dimension and amount, based on ethnicity and metabolic conditions, such as obesity and metabolic syndromes ${ }^{7}$. Each structure is fed by two arterioles and one venule within vascular stalks attached to the colon. These structures are commonly found on the sigmoid colon (57\%), cecum (26\%), ascending colon (9\%), transverse colon $(6 \%)$, and descending colon $(2 \%)^{7,8}$. These explain the pathophysiology of left lower quadrant abdominal pain experienced by patients, as was observed in these patients. 

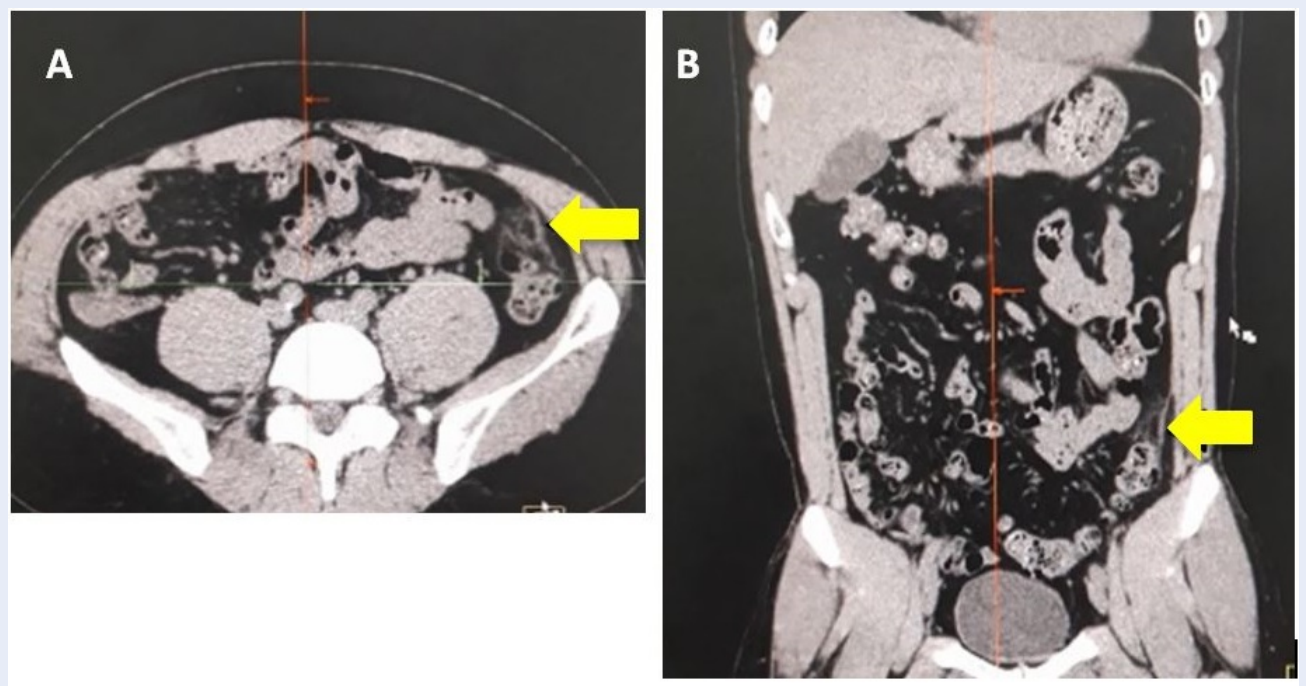

Figure 2: Non-enhanced abdominal CT scan of (A) axial and (B) coronal lesions. At L3-L4 level, CT scanning showed an oval lesion of fat attenuation with high-attenuation rim, measuring about $1.2 \times 0.5 \times 2.2 \mathrm{~cm}$, arising from the anterior wall of the descending colon, and surrounded by inflammatory fat stranding with no adjacent bowel wall thickening. CT scan results were consistent with epiploic appendagitis.

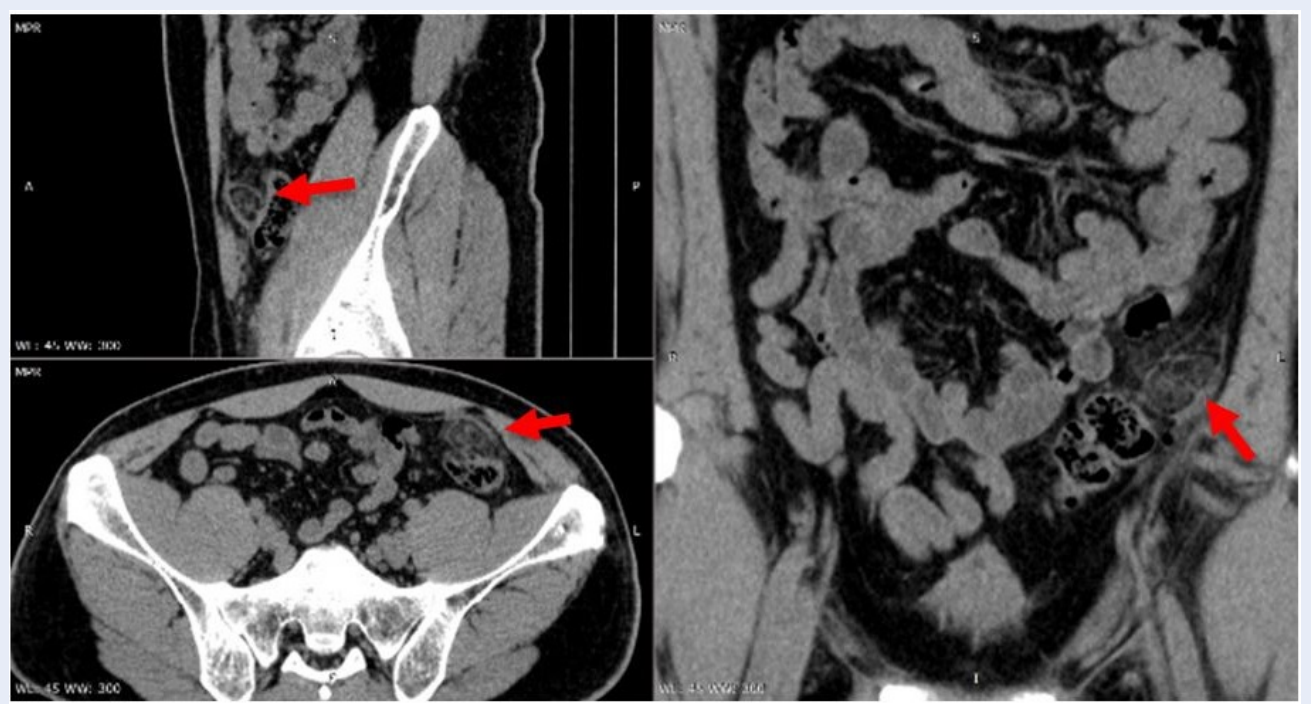

Figure 3: Non-enhanced abdominal CT scan showing fat attenuation, specifically an ovoid-like lesion with high-attenuation rim, measuring $1.7 \times 3 \times 3.16 \mathrm{~cm}$ in size on the anterior surface of the sigmoid colon. 
The terminal blood supply within stalks make appendices vulnerable to ischemic complications due to torsion or minor thrombosis ${ }^{7,9}$. Ischemia leads to an inflammatory state of the appendices known as primary appendagitis epiploicae. The secondary ones are commonly caused by post-operative adhesion, inflammatory processes from surrounding structures (such as diverticulitis, appendicitis, Crohn's ileitis, and pelvic inflammatory disease), extensive abdomen muscle training, and weight loss ${ }^{7,10}$. We did not find any risk factors in our patients so we concluded all of them as having primary appendagitis.

Appendagitis has been reported in $2-7 \%$ of patients initially diagnosed with acute diverticulitis and in 0.3 $-1 \%$ of patients with suspected acute appendicitis ${ }^{11}$. This is consistent with observations of our first and third patients. On admission, the first patient was suspected as having acute appendicitis while the third patient was suspected as having diverticulitis.

Epiploic appendices are not well-developed during growth periods and, therefore, the majority of cases develop during the fourth decade, predominantly among males ${ }^{7}$. Nevertheless, some publications have reported cases of younger age, from childhood age to older age (beyond 80 years old), especially in obese patients ${ }^{11-13}$. This kind of epidemiologic characteristic could be found in our patients. They were in their fourth decade in terms of age, but they did not have any risk factors such as obesity and metabolic syndromes.

The characteristic clinical findings are sudden acute abdominal pain that is worsened with movement. The pain is localized, non-migratory, and commonly found on the lower abdominal quadrant. Fever, nausea, vomiting, anorexia, and change of bowel habit are rarely found. In physical examination, it is possible to find local abdominal guarding. In addition, it has been reported that there can be slightly elevated leukocytes and C-reactive protein (CRP) level; the former was found in our first and third patients as a natural response to the inflammatory process $7,10,14$. Radiologic imaging, especially CT scanning as the modality of choice, plays an important role in establishing diagnosis of appendagitis. Normal appearance of appendices could not be found in the CT scans, but there were specific findings in the inflamed appendices. The most common and pathogenic findings, as observed in all of the 3 patients, was a fat-dense ovoidlike structure close to the colon. The structure was about $1.5-3.5 \mathrm{~cm}$ in diameter with thin high-density showing in the rim (1-3 mm thick), known as the hyperattenuating ring sign ${ }^{15,16}$. Although the hyperattenuating ring sign is pathognomonic, absence of this finding does not eliminate possibility of diagnosis. It looks more prominent than the thickening of the adjacent colon wall, due to reactivity to the inflammation process, and helps differentiate appendagitis from diverticulitis, appendicitis, and acute cholecystitis ${ }^{17}$.

Other modalities such as ultrasonography (US) and magnetic resonance imaging (MRI), although rarely used, could give useful information regarding diagnosis. Experienced ultrasonographers can find a noncompressible hyperechoic oval lesion adjacent to the colon located near pain localization ${ }^{18}$. On MRI findings, there was a fat-intensity ovoid structure with central hypointense dot and peripheral T1W1, as well as a central hyperintense dot and peripheral $\mathrm{T} 2 \mathrm{~W}$ fat suppression with rim enhancement on contrast ${ }^{7}$.

For the past 20 years, it has already been established that most appendagitis cases have a good response to conservative treatments and NSAID regiment, as was observed in our patients. Surgical treatment has usually been only performed for cases complicated with intussusception, abscess, and obstruction ${ }^{13,19}$. Conservative treatment could minimize surgery and anesthesia complications, and could reduce the length of stay and cost of treatment ${ }^{20}$.

Appendagitis must be detected earlier so that the condition does not worsen in the patients. In this study, all of the 3 patients had early-stage appendagitis which was confirmed by CT scan. Earlier detection of appendagitis recovered our patients immediately and minimized inappropriate invasive management like surgery.

\section{CONCLUSION}

The signs and symptoms of epiploic appendagitis are not specific and, therefore, clinical diagnosis of this disease has barely been established. Radiologic modalities could provide additional information for clinicians. The possibility of appendagitis as a diagnosis should be applied to each patient who presents with non-specific abdominal pain. Although as a disease it is rare, the proper clinical diagnosis of epiploic appendagitis could eliminate unnecessary surgical and invasive treatments for the patients since appendagitis responds well to conservative management.

\section{ABBREVIATIONS}

CT: Computed Tomography

CRP: C-reactive protein

US: Ultrasonography

MRI: Magnetic Resonance Imaging 


\section{ACKNOWLEDGMENTS}

None.

\section{AUTHORS' CONTRIBUTIONS}

Literature search, Clinical studies, Data acquisition, Data analysis, Manuscript preparation: Ronny. The author read and approved the final manuscript.

\section{FUNDING}

Not applicable.

\section{AVAILABILITY OF DATA AND MATERIALS}

Data and materials used and/or analyzed during the current study are available from the corresponding author on reasonable request.

\section{CONSENT FOR PUBLICATION}

Not applicable.

\section{COMPETING INTEREST}

The author declares that has no conflicts of interest.

\section{REFERENCES}

1. Ozturk M, Aslan S, Saglam D, Bekci T, Bilgici MC. Epiploic Appendagitis as a Rare Cause of Acute Abdomen in the Pediatric Population: Report of Three Cases. Eurasian J Med. 2018;50(1):56-58. PMID: 29531496. Available from: https: //doi.org/10.5152/eurasianjmed.2018.17247.

2. Almuhanna AF, Alghamdi ZM, Alshammari E. Acute epiploic appendagitis: A rare cause of acute abdomen and a diagnostic dilemma. J Family Community Med. 2016;23(1):4850. PMID: 26929730. Available from: https://doi.org/10.4103/ 2230-8229.172234

3. Goh VL, Rudolph CD. Epiploic Appendagitis. J Ped Gastroenter and Nutrition. 2011;53(1):1. PMID: 21694530. Available from: https://doi.org/10.1097/MPG.0b013e31820c5f59.

4. Coulier B, Ramboux A. Spontaneous Hemoperitoneum from Bleeding of a Pedunculated Epiploic Appendage. J Belg Soc Radiol. 2018;102(1):36. PMID: 30039048. Available from: https: //doi.org/10.5334/jbsr.1530.

5. Giambelluca D, Cannella R, Caruana G, Salvaggio L, Grassedonio $E$, Galia M, et al. CT imaging findings of epiploic appendagitis: an unusual cause of abdominal pain. Insights Imaging. 2019;10(1):26.

6. Patel NB, Wenzke DR. Evaluating the Patient with Right Lower Quadrant Pain. Radiol Clin North Am. 2015;53(6):11591170. Available from: https://doi.org/10.1016/j.rcl.2015.06.004; 26526431.

7. Martinez CAR, Palma RT, Silveira JPP, Sato DT, Rodrigues MR, Resende JHCd, et al. Primary epiploic appendagitis. J of Colo- proctology. 2013;33(3):161-166. Available from: https://doi. org/10.1016/j.jcol.2013.03.004.

8. Sand M, Gelos M, Bechara FG, Sand D, Wiese TH, Steinstraesser $\mathrm{L}$, et al. Epiploic appendagitis-clinical characteristics of an uncommon surgical diagnosis. BMC Surg. 2007;7:11. PMID: 17603914. Available from: https://doi.org/10.1186/1471-24827-11.

9. Akay S, Yilmaz C, Selek E, Erkan N. Torsion of Epiploic Appendages: An Overlooked Cause of Acute Abdomen. J Emergency Med. 2012;42(3):309-310. PMID: 20832965. Available from: https://doi.org/10.1016/j.jemermed.2010.05.086.

10. Lorente C, Hearne CB, Taboada J. Recurrent epiploic appendagitis mimicking appendicitis and cholecystitis. Proceedings (Baylor University Medical Center). 2017;30(1):4446. PMID: 28127129. Available from: https://doi.org/10.1080/ 08998280.2017.11929522.

11. Schnedl WJ, Krause R, Tafeit E, Tillich M, Lipp RW, WallnerLiebmann SJ. Insights into epiploic appendagitis. Nat Rev Gastroenterol Hepatol. 2011;8(1):45-49. PMID: 21102533. Available from: https://doi.org/10.1038/nrgastro.2010.189.

12. Nugent JP, Ouellette HA, O'Leary DP, Khosa F, Nicolaou $S$ McLaughlin PD. Epiploic appendagitis: 7-year experience and relationship with visceral obesity. Abdom Radiol (NY). 2018;43(7):1552-1557. PMID: 29043404. Available from: https://doi.org/10.1007/s00261-017-1355-5.

13. Issa IA, Berjaoui M-T, Hamdan WS. Primary epiploic appendagitis: from A to Z. Intern med case reports J. 2010;3:6769. PMID: 23754892. Available from: https://doi.org/10.2147/ IMCRJ.S11710.

14. Schnedl WJ, Krause R, Wallner-Liebmann SJ, Tafeit E, Mangge $\mathrm{H}$, Tillich M. Primary epiploic appendagitis and successful outpatient management. Med Sci Monit. 2012;18(6):CS48-CS51. PMID: 22648258. Available from: https://doi.org/10.12659/ MSM.882863.

15. Singh AK, Gervais DA, Hahn PF, Rhea J, Mueller PR. CT Appearance of Acute Appendagitis. American J Roentgenology. 2004;183(5):1303-1307. PMID: 15505294. Available from: https://doi.org/10.2214/ajr.183.5.1831303.

16. Neeraj N, Radha S, Anshuman K, N S. Primary Epiploic Appendagitis: Solving the Puzzle of a Benign Acute Abdomen. Open Access J of Surg. 2018;8(2):555731. Available from: https://doi.org/10.19080/OAJS.2018.08.555731.

17. Uehara R, Isomoto $H$, Yamaguchi N, Ohnita K, Fujita F, Ichikawa $\mathrm{T}$, et al. Epiploic appendagitis in a 27-year-old man. Med Sci Monit. 2011;17(10):CS113-CS115. PMID: 21959616. Available from: https://doi.org/10.12659/MSM.881968.

18. Choi YU, Choi PW, Park YH, Kim Jl, Heo TG, Park JH, et al. Clinical characteristics of primary epiploic appendagitis. J of the Korean Soc of Coloproctology. 2011;27(3):114-121. PMID: 21829765. Available from: https://doi.org/10.3393/jksc.2011. 27.3.114.

19. Erkan G, Gezen C, Bilgin SS. A Rare Cause of Abdominal Pain: Primary Epiploic Appendagitis (PEA). J Clin Anal Med. 2016;7(4):567-569. Available from: https://doi.org/10.4328/ JCAM.4436.

20. Clement Z. Atypical Presentations of Epiploic Appendagitis: Early Diagnosis and Non-Operative Management is the Optimal Therapy. Gastroenterology Res. 2012;5(2):79-81. PMID: 27785186. Available from: https://doi.org/10.4021/gr422w. 